\title{
DE ONDERNEMERSRAAD VOOR SURINAME EN ZIJNE VOORSTELLEN BETREFFENDE DEN GROOTEN LANDBOUW \\ DOOR
}

MR. DR. C. F. SCHOCH

De litteratuur over Suriname is dezer dagen weder met een belangrijk document verrijkt. De Ondernemersraad voor Suriname, waarover ik het vorige jaar in de WestIndische Gids het een en ander mocht mededeelen, heeft in Juli een request tot den Minister van Koloniën gericht met eene daarbij gevoegde uitvoerige nota, welke stukken thans in druk zijn verschenen.

Het is mij eene aangename taak aan het verzoek van de redactie van ons tijdschrift gevolg te kunnen geven om van deze studie een overzicht te geven. De nota zelve omvat 49 bladzijden folio druk en het overzicht kan dus niet anders dan beknopt aangeven, wat in het lijvige geschrift is verwerkt.

Bij de kennisneming van request en nota trekt reeds dadelijk tweeërlei de aandacht, waardoor deze stukken zich onderscheiden van de vorige, in deze eeuw verschenen, zeer belangrijke rapporten over de kolonie Suriname. Tot nog toe waren die rapporten bijna uitsluitend het resultaat van den arbeid van commissies of personen, die, door de eene of andere bijzondere aanleiding, hunne aandacht op een gegeven oogenblik, voor korteren of langeren tijd, speciaal op de in Suriname aanwezige toestanden hadden gevestigd, maar toch als buitenstaanders moesten worden aangemerkt. Thans hebben de belanghebbenden bij den landbouw, den handel en de nijverheid in de kolonie zich in den Ondernemersraad vereenigd en gezamenlijk hunne stem bij 's Lands Regeering doen hooren. 
In de tweede plaats wijken de thans verschenen stukken van vroegere rapporten af, doordat niet het geheele economische samenstel der kolonie tot grondslag van het onderzoek heeft gestrekt, maar slechts een onderdeel daar van, al is het een zeer belangrijk onderdeel, in studie is genomen.

Een en ander geeft aan de publicatie buitengewone belangrijkheid.

In zijn request aan den Minister spreekt de Ondernemersraad als zijne overtuiging uit, dat de economische ont wikkeling van de kolonie voor het overgroote deel afhankelijk is van den bloei van den grooten landbouw. Daarom is in de allereerste plaats de vraag in studie genomen, welke de redenen zijn waarom de aanwezige plantages over het algemeen slechts een kwijnend bestaan lijden en waarom Suriname voor opening van nieuwe landbouwbedrijven zoo weinig aantrekkelijk is. Aan ieder, wien het welzijn van Suriname oprecht ter harte gaat, klinkt deze mededeeling aangenaam en geruststellend in de ooren, n'en déplaise enkele raadgevers van tegenwoordig, zelfs in de koloniale raadzaal, die dit landbouwbelang niet op de eerste plaats stellen. Natuurlijk verdienen andere bronnen van welvaart, als de balata-industrie en de bauxietontginning, groote belangstelling en, zoo noodig, steun. Dat het die industrieën goed gaat geeft reden tot vreugde. De landbouw echter blijft voor Suriname het hoofdbestaansmiddel. Zonder bloeiende cultures zal de kolonie nooit loskomen van den zilveren keten, die haar te vast aan Nederland bindt.

Als resultaat van zijne studie is de Ondernemersraad tot deze conclusie gekomen, dat de langdurige ongunstige toestand van de kolonie voor een groot deel te wijten is aan de bestaande wettelijke bepalingen en voorschriften, zoowel op het gebied van immigratie en kolonisatie, als op het stuk van belastingen en arbeidswetgeving.

Van Bestuurswege kan op dit terrein zeer veel worden gedaan om de thans bestaande beletselen tegen een grooteren bloei der aanwezige plantages en tegen de opening van nieuwe ondernemingen op te heffen of althans belang- 
rijk te verminderen. Daarbij dient dan echter gebroken te worden met de gedachte, welke tot dus ver bij de behandeling van het Surinamevraagstuk al te vaak als axioma is vooropgesteld, dat elke maatregel, welke eene tijdelijke opoffering voor het moederland zou medebrengen, bij voorbaat uitgesloten moest worden geacht.

Bij de bestudeering van de bestaande wettelijke regelingen heeft de Raad in de eerste plaats critisch onder de oogen gezien de bestaande immigratieregeling. Welk doel de bevordering der immigratie heeft en in wiens belang, deze in de eerste plaats moet worden bevorderd, zijn vragen, die door Opperbestuur en Staten-Generaal niet altijd scherp genoeg gesteld en principiëel genoeg beantwoord zijn. Uitbreiding der immigratie is een eerste eisch voor toekomstige welvaart, met daarnaast vermeerdering van het in Suriname - en in de eerste plaats in den grooten landbouw - belegd kapitaal. Niet de bestaande ondernemingen, die helaas in de laatste jaren voortdurend minder immigranten noodig hebben, maar het Koloniaal Gouvernement zelf is de eerste belanghebbende bij de immigratie en moet die niet alleen geheel zelf in handen hebben, zooals reeds het geval is, maar ook geheel zelf bekostigen. De plantages kunnen, evenals tot nog toe, uitnemend dienen om de aangevoerde Javanen op te voeden tot zelfstandige kolonisten, maar het is absoluut onverdedigbaar, dat die plantages, welke de immigranten weder moeten los laten als zij goed geschoold en geacclimatiseerd zijn, bezwaard worden met de kosten van aanvoer en, bij een hercontract, zelfs meer dan die kosten aan het Gouvernement moeten terugbetalen en daarenboven, tijdens het gebruik van die immigranten, nog zoo zwaar van allen kant belast worden, dat behoorlijk winst maken vrijwel geheel uitgesloten is. Een en ander wordt in de nota met cijfers zoo duidelijk aangetoond, dat ieder onbevooroordeeld lezer het met de conclusie wel eens zal zijn: aanvoer van Staatswege en ook bekostiging van dien aanvoer van Staatswege, waar, blijkens de gegevens, tenminste $80 \%$ der aangevoerden kolonist worden en dus de blijvende bevolking doen toenemen. Men zou, om de kolonisatie nog sneller te doen plaats heb- 
ben, den contractduur met de plantages op 3 jaren kunnen bepalen in plaats van 5 jaren, zoodat de immigranten dan nog 2 jaren onder contract bleven bij het Gouvernement zelf, dat daardoor kracht zou kunnen bijzetten bij zijn toezicht op den arbeid van de aanstaande kolonisten. De kolonisatie zou kunnen plaats hebben, onder leiding van een bekwaam landbouwdeskundige, hetzij op vestigingsplaatsen,los van den grooten landbouw, hetzij op gedeelten van de plantages zelve, of wel zóó, dat de menschen zoo in de nabijheid van de plantages zich vestigen, dat zij een deel van hun tijd en arbeid kunnen geven aan de plantages.

$\mathrm{Na}$ de immigratie met de daaraan voor de plantages verbonden kosten behandelt de Raad in zijne nota de verdere lasten, welke op de plantages drukken:

$1^{\circ}$. de inkomstenbelasting voor rechtspersonen, zijnde eene winstbelasting van $7 \frac{1}{2} \%$ vermeerderd met eene uitkeeringsbelasting van $12 \frac{1}{2} \%$. Evenals eene dergelijke regeling voor Ned. Indië afgekeurd en vervangen is door eene eenvoudige vennootschapsbelasting zal dit ook voor Suriname noodig zijn. Dergelijke belasting zou dan wel op $10 \%$ kunnen worden gesteld.

$2^{\circ}$. het hoofdgeld, dat door de ondernemingen betaald moet worden voor de onder contract verbonden immigranten en dat eigenlijk nog eens eene suppletie is op de immigratiekosten. Dit hoofdgeld dient ten eenenmale veroordeeld te worden, terwijl daartegenover eene minimum-bijdrage als complement op de inkomstenbelasting dient te worden in het leven geroepen, dat door iederen werkbaren man en vrouw tusschen de 18 en 60 jaren oud, die niet op de gewone wijze in de inkomstenbelasting is aangeslagen, zou moeten worden opgebracht en wel voor een man bv. $f 5$. - en voor eene vrouw $f 2.50$ per jaar. De afschaffing in 1899 van eene dergelijke minimum-bijdrage, destijds hoofdgeld genaamd, door Gouverneur Tonckens, op m. i. verkeerde humaniteitsgronden, hebik steeds als een te betreuren fout beschouwd. Het hoofdgeld werd zonder te veel moeite geïnd en had het opvoedend element in zich, dat ieder, die kan, moet mededragen aan de gemeenschappelijke maatschappelijke lasten. Het denkbeeld, dat in Su- 
riname nog te veel aanhangers heeft: „lanti sa pai”, het Gouvernement zal wel betalen, moet zooveel en zoo spoedig mogelijk uit de wereld.Er is geen enkele reden waarom de eene ingezetene te veel moet betalen, omdat de andere, die ook zijn deel kan dragen, vrijgelaten wordt.

$3^{\circ}$. de geneeskundige belasting. Als er één belasting willekeurig is en ongerijmd en onbillijk, dan is het wel deze. De nota teekent dat in duidelijke, schrille kleuren. Meer dan de helft van de kosten van den geheelen burgerlijken geneeskundigen dienst in de kolonie wordt door de plantages in deze geneeskundige belasting gedragen. Afschaffing van deze belasting en opheffing van het instituut der geneesheeren-ambtenaren voor de plantages wordt terecht in de nota bepleit met daartegenover de aan de plantages op te leggen verplichting om, onder controle van Gouvernementswege, zelve voor de geneeskundige behandeling behoorlijk te zorgen. Dit systeem heeft in Deli de beste resultaten.

$4^{\circ}$. Met het sub 3 bedoelde behoort gepaard te gaan meerdere locale centralisatie van de ziekenhuisverpleging, doordat verschillende plantages zich daartoe vereenigen. Het Militair Hospitaal te Paramaribo, met zijne zeer kostbare verpleging, zal dan voor een groot deel kunnen worden ontlast, ten gerieve van het Gouvernement, maar ook van de planters, die de verpleging goedkooper kunnen doen plaats vinden, getuige de ondervinding met het centraal hospitaal op de onderneming Katwijk.

$5^{\circ}$. De invoerrechten maken de hoofdbron van inkomsten der kolonie uit en drukken zwaar op den levensstandaard der inwoners. Zij brengen driemaal zooveel op als de inkomstenbelasting. Zoodra het uit een fiscaal oogpunt mogelijk zal zijn, zal verlaging der invoerrechten van groot belang zijn voor de economische ontwikkeling van de kolonie.

$6^{\circ}$. De grondrente behoort ook tot de lasten, die zwaar op de plantages drukken, tenminste voorzoover deze in de eerste jaren van deze eeuw aan de uitnoodiging van het Koloniaal Gouvernement gevolg hebben gegeven om aan de bacovencultuur mede te doen. Die cultuur werd een 
groot fiasco en een deel van het verlies, in aan de plantages gedane voorschotten bestaande, werd als schuld op de plantages vastgelegd in den vorm van een zakelijke last met geleidelijke afbetaling van $f 5$. - per H.A. per jaar, berekend naar het aantal H.A., waarvoor het bacovenvoorschot genoten was. De schuld eindigt eerst als $f 200$ per H. A. zal zijn betaald, vermeerderd met $1 / 5$ van hetgeen de schuld op 1 Januari 1911 méér bedroeg dan dat bedrag en met de geheele toeneming van de schuld sedert dat tijdstip. Dit komt neer op eene extra belasting, die tal van jaren op vele plantages drukt.

De Ondernemersraad acht den tijd gekomen, dat het KoloniaalBestuur, daartoe door deRegeering gemachtigd, door deze schuld een streep haalt. De schuld is ontstaan uit goed vertrouwen in het Koloniaal Bestuur, dat het vooronderzoek naar de mogelijkheid van cultuur der destijds geïmporteerde en aangeplante bacovensoort had doen plaats hebben en bovendien waren de planters bij hun cultuur absoluut aangewezen op de instructies van de Gouvernements-deskundigen. Het geheel was dus feitelijk eene groote proef van Bestuurswege om eene nieuwe cultuur in Suriname te beginnen. Een en ander geeft alleszins aanleiding om ten deze royaal of nog beter billijk te zijn.

$7^{\circ}$. Als last moet ook worden beschouwd de superpreferentie, welke het Koloniaal Bestuur zich allerwege heeft aangematigd voor zijne vorderingen, uit welken hoofde ook, boven elke andere burgerrechtelijke vordering. Dat die voorrang voor belastingen geldt is natuurlijk, maar dat hij ook betreft de grondrente, de 15 centsvergoeding, de verschuldigde terugbetaling van geleende gelden, is onredelijk. Daarbij staat het Gouvernement in geen andere verhouding tot den debiteur dan elke andere crediteur. Deze door het Gouvernement zich zelven toegekende voorrang heeft veroorzaakt, dat plantages moeilijk geld van derden konden krijgen of bij meerdere behoefte niet meer konden ontvangen. En zoo gingen plantages te niet, omdat nieuwe crediteuren geen zekerheid konden verkrijgen met het nieuwe geld iemand anders te dienen dan het Ko- 
loniaal Gouvernement. Deze superpreferentie dient, op de wijze als in Nederland geschied is, zoo spoedig mogelijk te worden afgeschaft.

$8^{\circ}$. Ook in anderen zin zijn er lasten gelegd op de plantages, waardoor voor het vele, dat betaald moet worden, te weinig ontvangen wordt. Dit geldt de geheele arbeidswetgeving der contractarbeiders. Enkele zeer treffende bezwaren worden genoemd en vergeleken met de toestanden in Deli, als:

a. de arbeiders kunnen buiten hun werktijd hulp weigeren, wanneer die vereischt wordt bij dreigende rampen van hooger hand.

$b$. bij de regeling van het taakwerk wordt het normaal loon (80 cent) zoo toegekend, dat zelfs een middelmatig arbeider dat binnen den contractueelen werktijd kan verdienen en een ,ijverig en ervaren arbeider" dus meer moet kunnen verdienen. Als gemiddelde wordt dus aangenomen de arbeidsprestatie van een niet-ervaren, niet ijverig arbeider.

c. het uurloon bedraagt, volgens de daarvoor gemaakte berekening in Suriname $11 \frac{1}{2}$ cent, in Deli 4 cent;

de werkelijke kosten per arbeider bedragen in Suriname per werkuur 16, 9 en in Deli 7,1 cent.

$d$. het aantal arbeidsdagen bedraagt per jaar in Suriname gemiddeld 240, in Deli \pm 315 .

Dit lage getal arbeidsdagen voor Suriname is het gevolg van de regeling, dat alle $Z$ ondagen vrije dagen zijn plus de officiëele feestdagen, plus de eigen feestdagen derJavanen, waarbij dan nog door eene verkeerde interpretatie de ziektedagen komen. En dan komt daarbij nog de verplichte loonbetaling, zoo mogelijk op Zaterdagmiddag, waardoor de Zaterdag ook geworden is tot een halve werkdag.

e. de werkuren per dag: 7 uur veldarbeid tegenover 10 uur arbeid in gebouwen, zijn ook buitengewoon weinig in vergelijking met die in de Buitengewesten van Ned. Indië, waar de regeling geldt van een maximum van 10 uur voor bovengrondschen arbeid en van $8 \frac{1}{2}$ uur voor ondergrondschen en nachtarbeid.

Dan heeft men nog de bezwarende bepalingen omtrent 
het onnoodig hooge minimum dagloon voor mannen van 80 cent en voor vrouwen van 60 cent en de onnoodig drukkende ouderwetsche bepalingen omtrent voorziening in huisvesting en die betreffende voeding.

Alleen de opsomming van een en ander zal den meest verstokten illusionist, die meent, dat behoorlijke arbeid een vloek is in plaats van een zegen, doen zien, dat welvaart in Suriname op die wijze nooit kan komen.

Het samenstel van al die regelingen is eenvoudig absurd en slechts historisch te verklaren. Dat er danig zal moeten worden gereorganiseerd, wil men menschen van de daad met kapitaal naar Suriname zien komen, menschen, die bij ervaring weten, wat arbeid in de tropen beteekent en waard is, zal voor ieder, die van de nota kennis neemt terstond duidelijk zijn. De geheele arbeidswetgeving zal dienen te worden herzien en de Ondernemersraad meent, dat eene arbeidsinspectie beter werk onder de tegenwoordige omstandigheden zal kunnen verrichten dan het Immigratiedepartement, dat in de periode van Britsch-Indische immigratie voldoen kon, maar nu uit den tijd is.

Is het noodig, dat al het opgesomde aan lasten en bezwaren nù onder de oogen wordt gezien en eene reorganisatie in den aangegeven grooten omvang nù wordt ter hand genomen?

Het antwoord van den Ondernemersraad luidt zeer beslist in bevestigenden zin, omdat de omstandigheden thans in verschillende opzichten bijzonder gunstig zijn om een deel van het Nederlandsche kapitaal, de Nederlandsche energie en de Nederlandsche werkkracht te zien aangewend ten bate van de economische ontwikkeling van Suriname.

Die gunstige omstandigheden zijn:

$1^{\circ}$. dat Suriname thans in buitengewoon gunstige conditie verkeert ten opzichte van de omringende landen, omdat de kolonie een onbeperkt aantal immigranten voor bevolkingsuitbreiding kan verkrijgen, wat door de BritschIndische Regeering voor de naastbijgelegen Britsche koloniën onmogelijk is gemaakt. 
$2^{\circ}$. dat de vrije aanvoer van die contractarbeiders nog voorloopig verzekerd is, hoewel de handeling van de Britsch-Indische Regeering in Inlandsche kringen van Ned. Indië een diepen indruk heeft gemaakt en bij de voortschrijdende meerdere autonomie van Ned. Indië ten deze wel eens onaangename verrassingen zouden kunnen komen.

$3^{\circ}$. dat als zulke verrassingen zouden komen, men niet dan eerst het oog op Suriname als reserveland moet richten, maar Suriname dan gereed moet zijn om een deel van de tegenwoordige taak van Ned. Indië over te nemen.

$4^{\circ}$. doordat de cultures in Ned. Indië een tijdperk van grooten bloei beleven en groote winsten maken.

Door zijn contact met den Ondernemersraad voor Ned. Indië, is de Ondernemersraad voor Suriname in de gelegeheid, als aan de genoemde bezwaren door Regeering en Koloniaal Bestuur tegemoet gekomen wordt, zoo krachtig mogelijk in de kringen van het Oost-Indische kapitaal propaganda te maken voor de ontwikkeling van Suriname.

Zullen de aangegeven maatregelen en noodige wijzigingen veel kosten, is eene vraag, die natuurlijk opkomt bij den lezer van het voorafgaande? Ook daaraan wijdt de Ondernemersraad een deel van zijne nota.

Met zekerheid is natuurlijk ten deze niets vast te stellen. Alle voorstellen zijn bijv. gericht op de groote economische ontwikkeling van de kolonie. Hoeveel de stijging der inkomsten daardoor zal bedragen hangt van allerlei niet op cijfers vast te stellen factoren af. Het in het leven roepen van meerdere ondernemingen zal aan aanvoerkosten van immigranten meer vragen, evenals verkorting van den contracttijd op de plantages, terwijl de boven reeds genoemde meerdere aanvoer ook meer voor kolonisatie-uitgaven zal vereischen.

De oud agent-generaal C. van Drimmelen heeft de netto-baten voor de schatkist van iederen kolonist op $f 29$.per jaar geschat. In ieder geval geldt voor al deze maatregelen dat de cost gaet uit voor de baet. Voor deze productieve maatregelen zal de Nederlandsche Staat, en niet de 
kolonie de noodige gelden door leening moeten zien te verkrijgen. Wèl valt te berekenen wat in den nieuwen toestand aan inkomsten gemist zou worden.

Berekend wordt, dat bij afschaffing van de 15 centsvergoeding en van het hoofdgeld de kolonie een $f 340.000$ zal missen aan jaarlijksche inkomsten.

De afschaffing van de geneeskundige belasting zal geen extra-uitgaven voor het Gouvernement veroorzaken. Verschillende Gouvernementsgeneesheeren zullen kunnen vervallen of zullen door de ondernemingen worden overgenomen en op de kosten van het Militair Hospitaal zal flink kunnen worden bezuinigd.

De kwijtschelding van grondrente zal $\pm f$ 12.000.- per jaar aan begrootinsginkomsten ontnemen.

Daartegenover kan eene nieuwe 10\% vennootschapsbelasting, blijkens de in de nota gemaakte berekening, een $f$ 54.000.- 's jaars meer opbrengen dan hetgeen de plantages tegenwoordig aan inkomstenbelasting betalen.

De weder in te voeren minimumbijdrage als complement op de inkomstenbelasting kan, naar berekening, een $f$ 200.000.- opbrengen.

Tegenover de te missen $f 352.000$. - zou reeds dadelijk $f$ 254.000.- aan inkomsten gevonden zijn.

Alles wat de saneering van den kolonialen toestand in verband met den landbouw verder zal kosten, zal ruimschoots worden vergoed door de meerdere welvaart en de daaruit voortvloeiende meerdere inkomsten.

De nog niet door mij genoemde, in de nota ook zeer aanbevolen maatregel, tot wijziging van het onderwijs der immigranten-jeugd meer in landbouwrichting, zal weinig invloed hebben op de algemeene onkostenrekening.

Aan het slot van de nota worden de verschillende voorstellen nog eens geresumeerd. Ik acht deze conclusies van zooveel belang, dat ik mij niet weerhouden kan, die hier in extenso te doen volgen, met het daaraan toegevoegde slot.

„De hoofdlijnen van ons betoog zouden wij willen samenvatten in de volgende stellingen:

1. Het is niet een koloniaal Surinaamsch, doch een na- 
tionaal Nederlandsch belang, dat aan den tegenwoordigen treurigen toestand der kolonie Suriname, zoo op financiëel als op economisch gebied, ten spoedigste een einde kome, opdat:

$a$. de jaarlijks terugkeerende tekorten op de Surinaamsche begrootingen, welke Nederland moet bijpassen, zoo spoedig mogelijk verdwijnen;

$b$. te zijner tijd, wanneer om welke reden ook belegging van Nederlandsch kapitaal in Ned. Indië minder aantrekkelijk mocht worden, Suriname gereed zij om ten deze de taak van Ned. Indië zooveel mogelijk over te nemen.

2. Ter bereiking van het onder 1 gesteld dubbel doel is het noodig en gemotiveerd, dat Nederland zich tijdelijk een geldelijk offer getroost, bijv. door het aangaan ten laste van het moederland van een geldleening voor de economische ontwikkeling van Suriname.

3. Voor die ontwikkeling is in de allereerste plaats noodig een sterke toeneming der bevolking en dat wel in snel tempo; deze is alleen mogelijk door krachtige bevordering van Staatswege van de Javanen-immigratie,waardoor tegelijkertijd de belangen van het overbevolkte Java zullen worden gediend.

4. Daargelaten of rechtstreeksche vestiging van pas van Java aangevoerde immigranten aanstonds als vrije kolonisten aanbeveling verdient en practisch uitvoerbaar is, zal in elk geval de tot dusverre gebruikelijke methode, om de Javanen aan te voeren als contractarbeiders voor de plantages en eerst na afloop van hun contract en van hunne landbouwkundige opleiding op de ondernemingen hunne vestiging als kolonisten te bevorderen, hoofdzaak moeten blijven.

5. Daar echter de behoefte van de tegenwoordige ondernemingen aan nieuwe immigranten eerder af- dan toeneemt, is voor den Staat aanwakkering van de opening van krachtige nieuwe ondernemingen het aangewezen middel ter bevordering van immigratie op grooter schaal en in sneller tempo dan tot dusverre.

6. Suriname verkeert ten deze momenteel - vooral 
ook in vergelijking met hare Britsche naburen - in een gunstige positie:

$a$. doordat aanvoer van een vrijwel onbeperkt aantal contractarbeiders van Java - mannen en vrouwen mogelijk en, na de laatste principiëele beginselverklaring der Indische Regeering ook verzekerd is;

$b$. doordat de cultures in Ned. Indië een tijdperk van grooten bloei beleven en groote winsten maken;

c. doordat de Ondernemersraad voor Suriname door zijne connecties met den Ondernemersraad voor Ned. Indië er misschien in zal kunnen slagen, een deel van het nieuwe kapitaal, dat anders in Oost-Indië of elders belegging zou zoeken, naar Suriname te trekken.

7. Hoewel bodem en klimaat, zoomede de ligging van Suriname ten aanzien van het wereldverkeer en de mogelijkheid van aanvoer van Javaansche contractarbeiders op groote schaal over het algemeen niet ongunstige en ten deele zelfs zeer gunstige factoren zijn voor vestiging van nieuwe ondernemingen, meent de Ondernemersraad voor Suriname niettemin zijn poging in den onder $6 \mathrm{sub} c$ bedoelden zin afhankelijk te moeten stellen van de bepaling door het Opperbestuur en de Staten-Generaal van hun standpunt ten aanzien van de economische ontwikkeling van Suriname tegenover vorenstaande stellingen, en in het bijzonder van hun bereidwilligheid tot het brengen van een geldelijk offer als onder 2 bedoeld en tot bevordering van een grondige herziening - voor zooveel mogelijk in overeenstemming met het Koloniaal Gouvernement van de geheele bestaande wetgeving op het gebied van immigratie, kolonisatie, arbeidsregeling en belastingen.

8. Deze herziening betreft in hoofdzaak de volgende punten:

A. Ten aanzien van de immigratie en kolonisatie:

1. de erkenning van deze beide maatregelen als onderwerpen van Staatszorg, welke geheel ten laste van den Staat komen; wat niet uitsluit de medewerking van den grooten landbouw als middel om de immigratie gemakkelijker te maken en de immigranten op te voeden tot bruikbare kolonisten; derhalve: opheffing van het Immigratie- 
fonds, althans van de daaraan door de plantages verschuldigde bijdragen;

2. doelbewuste en deskundige leiding van de kolonisatie, met inachtneming ook van de hiermede verband houdende belangen van den grooten landbouw;

3 . ter bespoediging van de immigratie en bevordering van de kolonisatie verkorting van den termijn, waarvoor de contractanten door het Gouvernement worden verhuurd aan de plantages, van 5 tot 3 jaar;

4. hervorming van het onderwijsstelsel voor de kinderen der Javaansche immigranten in meer practische richting, ten einde dezen zooveel mogelijk voor den landbouw te behouden.

$B$. Ten aanzien van de arbeidswetgeving:

1. het openen van de mogelijkheid van een meer economisch gebruik der contractarbeiders ten einde te geraken tot verlaging van den kostprijs van het product, zoodat dit ook bij gemiddelde verkoopprijzen kan concurreeren op de wereldmarkt.

Hiertoe:

$a$. wijziging van het Immigratiebesluit, van het modelwerkcontract en van de verordening op den wekelijkschen rustdag, ten einde te verzekeren, dat inderdaad volgens de bedoeling van het Immigratiebesluit 300 dagen per jaar gewerkt wordt, en dat op Zon- en feestdagen gewerkt zal kunnen worden, wanneer het landbouwbedrijf dit noodig maakt, zonder dat daarvoor een latere werkdag vrijaf gegeven behoeft te worden;

$b$. verhooging van het maximum aantal arbeidsuren voor arbeid in het veld tot 10 uren per dag, zooals in andere tropische landen gebruikelijk is;

2. grootere vrijheid voor den werkgever ten aanzien van de wijze waarop hij voldoet aan zijne verplichtingen tot het verstrekken van geneeskundige behandeling en verpleging, vrije woning en voeding aan de contractanten.

3. invoering van een deskundige arbeidsinspectie.

C. Ten aanzien van de belastingen:

1. vervanging van de bestaande inkomstenbelasting 
voor rechtspersonen door een zakelijke vennootschapsbelasting van ten hoogste $10 \%$;

2. aanvulling van de bestaande inkomstenbelasting voor natuurlijke personen met een bescheiden heffing te betalen door ieder „werkbaar” ingezetene, die buiten de inkomstenbelasting valt en niet om speciale redenen behoort te worden vrijgesteld;

3. afschaffing van de geneeskundige belasting;

4. algeheele kwijtschelding van de bacovenschulden, subsidiair het openen van de mogelijkheid om de resteerende schulden op billijke voorwaarden af te koopen;

5. bevordering van het landbouwcrediet door opheffing van de superpreferentie van den fiscus boven hypotheek, naar het voorbeeld van de Nederlandsche Wet van 17 Maart 1923, Stbl. no. 91;

6. zoodra de stand der koloniale financiën het toelaat, verlaging van de invoerrechten.

De Ondernemersraad is overtuigd van de mogelijkheid om, door samenwerking van Regeering en ondernemerskapitaal, Suriname uit zijnen tegenwoordigen treurigen toestand op te heffen en tot nieuwen economischen bloei te brengen.

Zoolang echter de Nederlandsche Regeering bevordering van immigratie: middel en kolonisatie: doel niet erkent als een algemeen Staatsbelang van de allereerste orde en daarvoor een tijdelijk offer wil brengen; zoolang de kostprijs van het product wordt opgedreven door den druk van de immigratielasten en door verschillende heffingen, die met de rendabiliteit der ondernemingen geen rekening houden; zoolang ten slotte de arbeidstoestanden in de kolonie niet een algeheele wijziging ondergaan in den geest van die in de Oost-Indische Buitengewesten, acht onze Raad een behoorlijke rendabiliteit van het landbouwbedrijf in Suriname niet verzekerd en mag zij investeering van nieuw kapitaal niet aanraden.

Indien het Opperbestuur, de Staten-Generaal, en het Koloniaal Bestuur bereid worden bevonden om tot een 
grondige herziening der bestaande bepalingen en toestanden in den door ons aangegeven zin mede te werken, zal onze Raad niets onbeproefd laten om het thans voornamelijk in Oost-Indië werkend Nederlandsch kapitaal ook voor Suriname te interesseeren.

$\mathrm{Er}$ is echter periculum in mora, zoowel wat betreft de bestaansmogelijkheid voor de nog aanwezige oude landbouwberdijven, die laatstelijk door de abnormale droog te andermaal enorm geleden hebben, als ook ten aanzien van de mogelijkheid van aanvoer van contractarbeiders van Java, welke niet voor onbepaalden tijd verzekerd mag worden geacht.

Worden derhalve de in deze Nota samengevatte denkbeelden in beginsel aanvaard, dan zal de uitvoering der plannen tegelijkertijd in Nederland èn in Suriname èn ook, voor zoover omtrent enkele punten overleg met de Indische Regeering noodig is - in Nederlandsch-Indië, zonder verwijl en met den grootsten spoed moeten worden ter hand genomen."

Ik heb vertrouwen in het heldere inzicht van den Minister van Koloniën, Dr. J. C. Koningsberger; eveneens ben ik overtuigd van de instemming, die de voorstellen bij den tegenwoordigen Gouverneur, Baron van Heemstra en zijne raadslieden zullen vinden.

De Koloniale Staten in Suriname hebben in hun request aan den Minister van Koloniën van 14 Mei j.l., zooals in de nota wordt geconstateerd, reeds duidelijk uitgesproken, dat voor Rijkshulp voornamelijk in aanmerking mogen komen:

$a$. het verleenen van steun aan het kapitaal om in de kolonie een loonend emplooi te vinden en

$b$. het bevorderen van immigratie en kolonisatie.

Over twee hoofddenkbeelden van de nota van den Ondernemersraad bestaat dus reeds eenstemmigheid met dat vertegenwoordigend college.

Ook de Staten-Generaal vragen reeds jaren lang aan de Regeering om met afdoende plannen tot meerdere ontwikkeling van de kolonie te komen. 
De voorstellen zelve zijn van dien aard, dat $\mathrm{m}$. i. geen onbevooroordeeld kenner van Suriname de juistheid daarvan zou kunnen of willen betwisten. $Z$ ij hebben tenminste mijne onvoorwaardelijke instemming en die van alle in den Ondernemersraad vereenigde belanghebbenden en belangstellenden in de kolonie.

De voorteekenen voor eene eindelijke, gunstige regeling zijn dus in alle opzichten gunstig.

Moge ieder, die ten deze verantwoordelijkheid draagt, beseffen, dat het nu de tijd is om de zaken aan te vatten.

Baden (Aargau),

14 Juli 1926. 